\title{
Audit of Emergency Obstetric Referrals- A Pilot Study From Tertiary Care Centre of North India
}

\author{
NEELAM AGGARWAL ${ }^{1}$, RIMPI SINGLA ${ }^{2}$, LAKHBIR DHALIWAL ${ }^{3}$, VANITA SURI $^{4}$
}

\begin{abstract}
:
Objective (s): The aim of the study was to find out the characteristics of emergency obstetric referrals, to evaluate the lapses in the existing referral system and to suggest the plausible solutions to improve the obstetric health care delivery system in India.

Materials and methods: This prospective descriptive study was carried out in the Department of Obstertrics and Gynaecology PGIMER Chandigarh India from September 2012 to December 2012. All the obstetric emergency referrals to our institute, a tertiary care centre in North India were critically reviewed for reason for referral, adequacy of care provided before referral, lapses in management, factors behind suboptimal care and remedial measures are suggested.

Results: There were 232 emergency referrals available for analysis. Of these $76 \%$ patients were referred directly to the institute, the highest level in referral chain in the region. Mean age was $26 y r s, 28.6 \%$ of the patients were illiterate. In $75.5 \%$ of cases, the management of obstetric emergency before referral was suboptimal or poor. In 16\% of cases patient failed to seek medical help timely despite emergency. In $40 \%$ of cases there was undue delay in referring or failure to provide even the basic care. Anticipated premature delivery and hypertensive disorders of pregnancy were the most common diagnosis at referral.

Conclusion: Results from this pilot study shows that in spite of the most extensive health care infrastructure and so- called hierarchal referral system, there is gross inadequacy in referral system in India.
\end{abstract}

Key Words: pregnancy, obstetrics, emergency referrals

Introduction:

The Millennium Development Goals (MDGs) were set at the 2000 Millennium Summit ${ }^{1}$. Reproductive health was given priority. Progress towards MDG 5 of improving maternal health is monitored through achievement of two targets. Target 5.A is reduction of maternal mortality ratio by three quarters between 1990 and 2015. Target 5.B is to achieve universal access to reproductive health by 2015.Despite showing a decline of $47 \%$ from levels in 1990, globally, an estimated 287000 women died during pregnancy and childbirth in $2010^{2}$.

Obstetrical emergencies are most of the times lifethreatening, not only for the patient herself, but also for the unborn. These also reflect the actual status of maternal health services in the region.
India has one of the most extensive health infrastructures- a three-tier hierarchical referral system for the provision of efficient health services. Further the Government of India has launched the National Rural Health Mission (NRHM) for the period of 20052012 to revise the architecture of existing health care delivery system ${ }^{3}$.

Despite all these efforts, there is grave underutilization of community health centers ( $\mathrm{CHCs}$ ), the first referral units. In our institute, we have been receiving patients in obstetric emergency unit from every health care level. We took a serious note of some common lapses in either seeking or providing emergency care and undue delay in referring the patients leading to deterioration of their condition.

1. Assistant Professor, Obstetrics \& Gynaecology

2. Assistant Professor, Obstetrics \& Gynaecology

3. Professor Head, Obstetrics \& Gynaecology

4. Professor, Obstetrics \& Gynaecology

Departments of Obstetrics\& Gynaecology, PGIMER, Sector 12, Chandigarh, 160012, INDIA 
There was an emergent need to look into the deficiencies in care at the referring centers, so as to suggest some definitive measures to reduce maternal morbidity and mortality and to sensitize the policymakers towards the need to strengthen the existing health care system. Hence, this pilot project was undertaken to critically evaluate the characteristics of emergency obstetric referrals.

\section{Materials and methods:}

This prospective descriptive study was carried out in the Department of Obstertrics and Gynaecology PGIMER Chandigarh India from September 2012 to December 2012.All patients (referred with obstetric emergency) or their attendants were interviewed and their referral slips were reviewed. Referring person was contacted whenever required and feasible. Demographic profile of the referred patients was studied. Findings were recorded on a predesigned proforma.

\section{Referral characteristics:}

We studied the characteristics of the referrals as the diagnosis at referral, adequacy of care provided before referral, lapses in care. Specific reasons behind referring the patient with any obstetric complication such as need for blood, or Intensive Care Unit (ICU) care, or need for neonatal ICU care were looked in to.

The interval between time of referral and actual time of admission in the institution was recorded. Distance from the referring center to the institute was calculated. Note was also made of adequacy of care during transit and presence of accompanying health personnel in case of serious obstetric morbidities. The reasons behind deficiencies were studied and thus, possible measures for improvement were arrived at.

\section{Results:}

There were 232 referrals available for analysis. The mean age of the patients was 26 yrs. Nearly 29\% patients were illiterate and $28 \%$ studied only up to primary level. Demographic profile of all the patients is described in Table 1 . As many as $76 \%$ of patients were referred directly, hence, bypassing the intermediate levels of referral chain. Distance travelled by patient for reaching the institute ranged from $3 \mathrm{kms}$ to $350 \mathrm{kms}$ (Table II).In majority of cases (84\%), there

Table-I

Baseline patient characteristics

\begin{tabular}{llcc}
\hline Parameter & & \multicolumn{2}{c}{ Result } \\
\cline { 3 - 4 } Age $($ mean \pm SD) yrs & & $\mathrm{N}$ & $\%$ \\
\hline Parity & Nulliparous & 96 & 41.3 \\
& Multiparous & 136 & 58.6 \\
Education & Illiterate & 58 & 28.628 .1 \\
& Primary $^{*}$ & 56 & \\
& Secondary $^{*}$ & 58 & 29.1 \\
& Graduate/ Post graduate $^{*}$ & 28 & 14 \\
\hline
\end{tabular}

* Primary: $5^{\text {th }}$ standard, ** secondary: $10^{\text {th }}$ standard

Table-II

Referral characteristics

\begin{tabular}{llcc}
\hline Characteristic & & \multicolumn{2}{c}{ Result } \\
\cline { 3 - 4 } & & $\mathrm{N}$ & $\%$ \\
\hline Type of referral & Primary & 176 & 75.9 \\
& Secondary & 56 & 24.1 \\
Need for accompanying health personnel & & 114 & 49 \\
Availability of health personnel & & 18 & 7.8 \\
Distance travelled by patient for reaching & & 68.1 & \pm 59.28 \\
hospital (kilometers) (Mean \pm SD) & & $\mathrm{N}$ & $\%$ \\
& Good & 57 & 24.5 \\
Level of care & Suboptimal & 72 & 31.1 \\
& Poor & 103 & 44.4 \\
\hline
\end{tabular}


were no accompanying health care personnel despite necessity. Only $24.5 \%$ of patients received optimal emergency care before referral. Most common diagnosis cited at the time of referral was anticipated premature delivery, followed by hypertensive disorders of pregnancy (Table III). Many patients had multiple complications at the time of referral. Hypertensive disorders of pregnancy included 16 patients with eclampsia. Complications of labor included obstructed labor, rupture uterus, breech head entrapment (hydrocephalus was the cause), cephalopelvic disproportion, scar dehiscence, complete perineal tear; complications related to abortion included failed medical termination of pregnancy (MTP), Failed MTP with Intra uterine device (IUCD) in situ, inevitable abortion, septic induced abortions, incomplete abortion. Many patients were referred with postoperative complications like acute renal failure, suspected urinary tract injury, septicemia, ARDS.

Table-III

Diagnosis at the time of referral

\begin{tabular}{lcc}
\hline Diagnosis & $\mathrm{N}$ & $\%$ \\
\hline Prematurity & 80 & 34.5 \\
Hypertensive disorders of pregnancy & 64 & 27.6 \\
Intra uterine growth restriction & 24 & 10.3 \\
Medical disorders complicating pregnancy & 24 & 10.3 \\
Antepartum hemorrhage & 23 & 9.9 \\
Anemia & 23 & 9.9 \\
Post partum hemorrhage & 14 & 6.0 \\
Complications of labor & 13 & 5.6 \\
Fetal distress & 12 & 5.2 \\
Puerperal sepsis & 9 & 3.9 \\
Complications related to abortions & 8 & 3.4 \\
Post- operative complications & 5 & 2.1 \\
HIV/ HBsAg positive & 3 & 1.2 \\
\hline
\end{tabular}

Most of the patients (36\%) were referred for better neonatal care either due to anticipated preterm birth, intra uterine growth restriction (IUGR) or fetal distress. Rest all were referred for maternal reasons like need for ICU care, need for blood and blood components, high risk for surgery, associated medical or surgical diseases (Table IV). While auditing the referral critically for any deficiencies, we derived a conclusion that there was serious lapse in emergency management in $40 \%$ of cases. Fifteen percent of the referrals were unnecessary as they could have been managed within the facilities and infrastructure available at the referring center (Table V).

\section{Discussion:}

We found suboptimal or poor management before referral in nearly $75 \%$ of the referrals. This was due to inappropriate management or inadequate documentation, or delay in referral. There was a failure in giving antihypertensive and/or MagS04 in case of eclampsia, antibiotics in case of prolonged leakage or infections, administering antiretroviral therapy to women with HIV infections. Patients with haemorrhage had not received adequate resuscitation measures. Things were further worsened by lack of proper documentation of the treatment as this can lead to repetition of treatment sometimes. The delay in the referral results in delay in treatment leading to irreversible complications. This delay was due to delay in identifying the high-risk situation (like abruptio placentae, heart disease), or delay in initiating treatment (antihypertensive, anticonvulsants), or delay in referring (like patient with obstructed labor, premature rupture of membranes kept on observation and referred later when delivery was imminent) or delay in transferring (due to lack of transport facility). Specific guidelines for "whom to refer", "how to refer" "when to refer" and "where to refer" would be helpful in making timely referral. Lack of adequate staff and equipment may be responsible for delay in initiating treatment. In adjoining state of Himachal Pradesh, only $49 \%$ of villages have some form of government health facility, either sub center, or primary health center (PHC), or $\mathrm{CHC}$, or referral hospital. ${ }^{4}$

Around $49 \%$ patients were referred in such conditions (convulsions, hemorrhage, shock) mandating the presence of health care personnel during transit, but only $8 \%$ patients were accompanied by the same. Before shifting the patient, on-going emergency treatment should be ensured (like fluid infusion, oxygen, emergency drugs) that was lacking in most cases.

Some referrals were found to be unnecessary (15\%) as the required infrastructure or man power was known to be available at the referring center and in some cases the diagnosis was wrong (2.5\%). Mostly the discrepancy was in relation to the diagnosis of abnormal labor, for example, some patients referred with non-progress of labor or obstructed labor or fetal distress did not have any evidence of the same. Patients with labor having HIV/HBsAg infection were referred for no reasons. Such patients received in emergency for the first time had not received antiretroviral therapy for prevention of transmission and hence care remains suboptimal. Mechanisms to monitor referral to reduce unnecessary referral and insist on necessary ones should be in place. 
Nearly $76 \%$ of patients were referred directly to PGIMER, thus, breaching the hierarchy of referral chain. Although sometimes bypassing the intermediate levels of care is necessary if the desired facility is available only at higher center, but such reason cannot account for such a high figure of $76 \%$. The National Family Health Survey-3 carried out by the Dept. of Health and Family Welfare showed suboptimal functioning of $\mathrm{CHCs}$ and $\mathrm{FRUs}^{5}$.A study conducted in three referral centers in Lucknow ${ }^{6}$ revealed that only one tenth of the patients attending the secondary and tertiary level public health facilities were referred by someone. Faith on the doctors and health facility (81\%) and availability of the specialists (54.5\%) were cited as the major reasons for direct visit to the referral facility. This study pointed out grave underutilization of $\mathrm{CHCs}$ "the first referral centre". This is bound to put the pressure on the specialized health services.

Looking at the reasons behind emergency referrals, we found that patients were referred with hypertension or related complications. As many as 16 patients came with eclampsia that is a major preventable cause of maternal mortality. Around 10\% came to emergency with anemia- related complications that is again preventable. Another preventable reason for referral in $2.6 \%$ was complications of abortion (mostly septic induced abortions). Reproductive and Child Health Programme II outcomes (2007- 2008) show that only $47.3 \%$ of women use any modern contraceptive method and that total unmet need for family planning - (both spacing methods and terminal methods) was $21.5 \% 4$.

In the index study, more than one-third of referrals were for better neonatal care, expressing the need for upgradation of other hospitals (District hospitals DH or above) with advanced neonatal care facilities. Another $11 \%$ patients were referred for blood or blood components. In District Level Household and Facility Survey (2004- 2008) in Chandigarh itself, among 5 villages, none of the $\mathrm{CHCs}$ were having blood storage facility ${ }^{4}$. In nearby state of Haryana, only $19 \%$ of FRUs are having blood storage facility ${ }^{4}$. Although only $11 \%$ of patients were referred especially due to need of blood, there were many more (nearly $26 \%$ came with hemorrhage or anemia) who were referred for different reason but could not have been managed without blood bank facility. Obstetric hemorrhage cannot always be predicted but can be fatal. Centers providing obstetric care should have back up of blood bank.
Need of the hour is to strengthen the existing CHCs and PHCs with man power and equipment and uninterrupted supply of consumables, rather than increasing the number of beds and buildings. The importance of a two- way referral system cannot be over emphasized. Some of the cases need to be followed up at the higher level forever. But many would be able to be sent back for follow up to the primary level once the acute crisis is over. Current referral system is more like a transfer system rather than referral system. With this the patients tend to lose their confidence on the lower centers resulting in under utilization of these centers ${ }^{7}$. Agood and well sustained referral system needs referral- protocols, improved support (especially transportation), community awareness, and feedback system ${ }^{8}$.

Next vital measure to reduce maternal morbidity and mortality is to ensure adequate coverage of maternal health care services. Some initiatives under $\mathrm{NRHM}^{3}$ are already in place like Accredited Social Health Activist (ASHA) workers, but still the antenatal coverage is poor. There was almost no change in antenatal care coverage in either urban or rural areas between NFHS-1, 2 and NFHS-3. ${ }^{9}$ Nation-wide only $19 \%$ of women had full antenatal check-up ${ }^{4}$. We observed an undue delay in seeking medical help even in case of emergency like antepartum hemorrhage, or labor and leakage, or even convulsions.

Reproductive and Child Health programme aimed at reduction of MMR 254/100,000 (2006) to 100/100,000 by 2012 and $100 \%$ institutional delivery rate. We had 8/232 (3.4\%) referrals due to complications (mostly sepsis) of delivery at home by untrained person. We perceive this figure as the tip of the iceberg as most seriously complicated patients came to us. Previous surveys have shown home-delivery in India to be $53 \%{ }^{4}$. Illiteracy is the most important factor behind home deliveries and delay in seeking medical help. Nearly $30 \%$ of referred patients were illiterate, $28 \%$ had studied only up to primary level. Seven out of 8 patients who had delivery at home were illiterate, rest one studied up to primary level. The existing national value of female literacy rate (65\%) needs to be improved ${ }^{9}$.

Approximately $10 \%$ of the emergency referrals were due to medical disorders or their complications. It is important to identify such high-risk cases at primary health care level and refer them to higher specialty for timely management. This would avoid many 
emergencies and indirect maternal deaths (deaths occurring during pregnancy that are not related to obstetric cause).

In conclusion it can be said that the current referral system is deficient in many aspects. There was serious lapse in emergency obstetric management in the form of failure to identify high risk situation, inadequate treatment before referral or inappropriate delay in referring. Treatment during transit to referral center is largely being ignored. Unnecessary referrals put significant burden on the resources at referral center and hence, should be discouraged. Augmentation of ambulance services and requisite staff for the same should be a priority.

\section{References:}

1. United Nations General Assembly. (2000) Resolution adopted by the General Assembly: United Nations Millennium Declaration (A/RES/ 55/2). http://www.un.org/millennium/declaration/ ares552e.htm.

2. The Millennium Development Goals Report (2012); www.un.org/millenniumgoals

3. National Rural Health Mission. http://nrhm.gov.in

4. International Institute for Population Sciences (IIPS), (2010). District Level Household and
Facility Survey (DLHS-3), 2007-08: India: Mumbai: IIPS. http://www.iipsindia.org

5. International Institute for Population Sciences (IIPS) and Macro International. (2007) National Family Health Survey (NFHS-3), 2005-06: India: Volume I Mumbai: IIPS. http://hetv.org/india/nfhs/ nfhs3/NFHS-3-IN

6. Bhola N, Kumari R, Nidha T. Utilisation of the health care delivery system in a district of North India. East Afr J Public Health. 2008; 5(3):14753.

7. A Study to Review The Health Care Delivery System by Punjab Health Systems Corporation (PHSC) (2008), Punjab, National Institute of Health and Family Welfare, New Delhi, uww.nihfw.org

8. Orientation of referral system-Rajasthan Health System Development Project (RHSDP)(State Institute of Health and Family Welfare, Rajasthan) (May 2005); www.rajswasthya.nic.in/ rhsdp.htm

9. Key Indicators for India from NFHS- 3, National Family Health Survey, 2005- 2006 http://hetv.org/ india/nfhs/nfhs3/NFHS-3-Key-Indicators-India.pdf

10. Census of India 2011, Provisional Population, Totals www.censusindia.gov.in 